Brit. J. prev. soc. Med. (1955), 9, 191-195

\title{
MENTAL ILLNESS AND SOCIAL CLASS IN BRISTOL
}

\author{
BY
}

\author{
E. H. HARE
}

From the Bristol Mental Hospital

During the past 40 years a number of studies have supported the general hypothesis that the incidence of mental illness differs among people in various occupational groups. In particular, these studies suggest that schizophrenia is more common among the lower-paid groups but that manic-depressive psychosis is more or less equally distributed among all groups. The evidence for this is briefly summarized below.

Tietze, Lemkau, and Cooper (1942) have reviewed some early investigations, but, as Clark (1948) points out, their conclusions can be criticized on the grounds that no allowance was made for differences in age-distribution among the occupational groups. Later studies, however, are not subject to this criticism. Tietze, Lemkau, and Cooper (1941) showed that, among 180 psychotic and 234 neurotic cases active during the year 1936 and resident in a district of the city of Baltimore, a significantly high proportion were drawn from the lower income groups. Studying over 12,000 male first admissions to Chicago mental hospitals during the years 1922 to 1934, Clark (1949) showed a high negative correlation between income and the incidence of schizophrenia in nineteen occupational categories; between income and manic-depressive psychosis, on the other hand, the correlation was practically zero. This author also showed that very similar correlations held when only the lowest ten of the nineteen occupational groups were considered, thus disposing of the criticism that schizophrenics in the highest income groups are missed because they are cared for outside the city, for of the families in his ten lowest groups, practically none would have been able to afford such private treatment. Hollingshead and Redlich $(1953,1954)$, in a study of nearly 2,000 psychiatric cases (including both in- and outpatients) under treatment on a certain date in New Haven, Connecticut, found a very significant excess of schizophrenics among the lower social groups (definied in terms of occupation, education, and place of residence).

From Great Britain the only evidence bearing on this subject appears to be that of the RegistrarGeneral (1953), derived from analysis of the Mental Health Index Cards for the year 1949. The figures (for males only) show the schizophrenia rate to increase markedly from Social Class I to Social Class V; the rates for manic-depressive psychosis and for neurosis show the same trend but to a much less marked degree. However, as the RegistrarGeneral points out, various factors limit the trustworthiness of these figures:

(a) in 10 per cent. of the (male) cases, no occupation had been recorded and so no social class could be assigned;

(b) there is often doubt as to the accuracy of the occupation recorded, or the information is not sufficient to allow the class to be assigned with confidence;

(c) there is little uniformity of diagnosis throughout the country;

(d) the hospital facilities and hence the selection of patients for admission vary throughout the country.

The present study is thought worth reporting because it adds to the meagre British evidence, and, being concerned with the population of a single city served predominantly by one mental hospital, avoids some of the limitations of the RegistrarGeneral's report.

\section{MeTHOD}

In principle, the method was to determine the social class and diagnosis of all male patients admitted during a 5-year period to mental hospitals who were resident in Bristol at the time of their admission. The investigation was confined to males because for married female patients the husband's occupation was not usually recorded in the statement of particulars. The details of technique are as follows: 
(a) Definition of a Case.-For the purpose of the study, a "case" was defined as "a first admission of a patient, from an address within the city boundary of Bristol," to a mental hospital". No simple definition of a psychiatric "case" can be entirely adequate. "Mental hospital" was taken to mean a hospital or nursing home which accepted wholly or predominantly cases recommended by a psychiatrist. There are several nursing homes in or near Bristol which accept aged patients who might in some instances be suffering from a psychiatric illness, but these nursing homes are not included in the survey. Patients attending the Bristol Day Hospital only were also excluded, but those admitted to the 80-bed Neurosis Unit were included.

(b) Case-Finding.-The survey was confined to a 5-year period, 1949-1953. This period was convenient because it centred in the 1951 Census and because during this time the psychiatric facilities in Bristol were practically unchanged. Of the psychiatric cases admitted to hospital, the great majority came to the Bristol Mental Hospital. Every effort, however, was made to trace cases admitted to private mental hospitals; the co-operation of the psychiatrists practising privately in Bristol and of the Medical Superintendents of nine private mental hospitals enabled this to be done with reasonable completenessit is not possible to determine the precise coverage, but I believe that the 32 private-patient cases found represent the great majority of the total private cases. Altogether, 1,264 male cases were found.

(c) Determination of Social Class.-This was done from the occupation, according to the Registrar-General's "Classification of Occupations" (General Register Office, 1951). For students and school-boys, the father's occupation was used. In the case of retired men, the occupation which they had pursued for most of their working lives was used. Where there was any doubt about the correct grading of an occupation as recorded on the statement of particulars or on the Mental Health Index Card, recourse was had to the case history; if this proved insufficient, the patient or his relatives were seen by a social worker. In 32 cases ( $2 \cdot 5$ per cent.), however, it proved impossible to assign a social class; five of these were private cases.

As a check on the accuracy of the Mental Health Index Card, a social worker (familiar with the RegistrarGeneral's classification of occupations and industries) interviewed 100 consecutively admitted patients (or relatives, if the patient was mentally inaccessible); the occupations as stated to her were then compared with those given on the index cards. In four instances, the information on the index card proved to be insufficient or misleading (e.g. a bricklayer's mate was described as a builder); but these errors were of the type that would have been checked from the case sheet and none would have led to a wrong final grading. This sample check suggests that the social class grading of all patients was reasonably accurate.

(d) Diagnosis.-The diagnostic categories were based on those of the International Statistical Classification of

\footnotetext{
* The city boundary was altered slightly in 1951, but the effect is negligible.
}

Diseases and Injuries (World Health Organization, 1949).

Five categories were used:

Schizophrenia, (including schizo-affective disorder and paraphrenia),

Manic-depressive psychosis (including involutional melancholia and atypical and unspecified depression),

Senile and arteriosclerotic psychosis,

Neurosis (including neurotic or reactive depression),

All other diagnoses.

Psychiatrists are notoriously apt to differ on diagnosis because of the lack of objective criteria and of agreement on fundamental theory; these differences are increased by regionalism, and each centre of psychiatric activity is apt to develop its own local diagnostic climate (e.g. Strömgren, 1948). In the present study, however, the diagnoses were made for the most part by a group of physicians working together in the same hospital and with frequent opportunities for the interchange of clinical opinion. It would seem reasonable to suppose that these conditions lead to greater uniformity of diagnosis than obtains in the country as a whole. Apart from this, the greatest single diagnostic difficulty was the allocation of certain cases of depression to the manicdepressive or to the neurotic category; the doubtful cases, however, did not form more than about 10 per cent. of the numbers in the two categories.

\section{RESULTS}

Table I (opposite) shows the observed and expected numbers of cases in different social classes. Because of the relatively small totals, the cases in Classes I and II have been combined, as have those in Classes IV and V. The "expected" number in a given social class is defined as the number of cases of a particular diagnosis that might have been expected to occur if the given social class had experienced within each age group the same case rate as that of the male population of Bristol as a whole. The data for the calculations was obtained from the 1951 Census One per cent. Sample Tables (General Register Office, 1952) and the 1951 Census County Report for Gloucestershire (General Register Office, 1954a). In calculating the expected numbers, the assumption was made that the agedistribution within the social classes in Bristol was the same as that in England and Wales as a whole.

Table I shows that schizophrenic cases were less than expected in the upper three social classes and much more than expected in the lower two, and that this distribution is very unlikely to have occurred from chance. For manic-depressive and senile psychoses, on the other hand, the observed distribution among the classes was not significantly different from that to be expected on a random distribution. For neurosis, the distribution is significantly different from random, but unlike schizophrenia, an excess of observed over expected cases occurs in Class III. 
TABLE I

OBSERVED AND EXPECTED NUMBERS OF CASES BY DIAGNOSIS AND SOCIAL CLASS

Males aged 15 and over, occupied and retired

\begin{tabular}{|c|c|c|c|c|c|c|c|c|c|c|c|}
\hline \multirow{2}{*}{\multicolumn{5}{|c|}{ Diagnostic Category }} & \multirow{2}{*}{\multicolumn{2}{|c|}{ Number of Cases }} & \multicolumn{3}{|c|}{ Social Class } & \multirow{2}{*}{$x^{2}$} & \multirow{2}{*}{$\boldsymbol{P}$} \\
\hline & & & & & & & I and II & III & IV and $V$ & & \\
\hline Schizophrenia & $\cdots$ & . & . & $\cdots$ & $\begin{array}{l}\text { Observed (210) } \\
\text { Expected }\end{array}$ & $\cdots$ & $\begin{array}{ll}17 \\
31 \cdot 6\end{array}$ & $\begin{array}{l}106 \\
123 \cdot 7\end{array}$ & $\stackrel{87}{54 \cdot 7}$ & $28 \cdot 35$ & $P<0.001$ \\
\hline \multicolumn{3}{|c|}{ Manic-depressive Psychosis } & $\cdots$ & $\cdots$ & $\begin{array}{l}\text { Observed (352) } \\
\text { Expected }\end{array}$ & 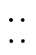 & $\begin{array}{l}66 \\
68 \cdot 2\end{array}$ & $\begin{array}{l}189 \\
179 \cdot 4\end{array}$ & $\begin{array}{r}97 \\
103 \cdot 7\end{array}$ & $1 \cdot 02$ & $0.5<P<0.7$ \\
\hline \multicolumn{5}{|c|}{ Senile and Arterio-sclerotic Psychosis .. } & $\begin{array}{l}\text { Observed (145) } \\
\text { Expected }\end{array}$ & $\cdots$ & $\begin{array}{l}24 \\
30 \cdot 4\end{array}$ & $\begin{array}{l}75 \\
67 \cdot 7\end{array}$ & $46 \cdot 9$ & $2 \cdot 15$ & $0.3<P<0.5$ \\
\hline Neurosis $\quad \ldots$ & $\cdots$ & $\cdots$ & . & $\cdots$ & $\begin{array}{l}\text { Observed (329) } \\
\text { Expected }\end{array}$ & $\cdots$ & $\begin{array}{l}39 \\
57 \cdot 3\end{array}$ & $\begin{array}{l}200 \\
183 \cdot 0\end{array}$ & $\begin{array}{l}90 \\
88 \cdot 6\end{array}$ & $7 \cdot 45$ & $0.02<P<0.05$ \\
\hline Other Diagnoses & $\cdots$ & $\cdots$ & . & $\cdots$ & $\begin{array}{l}\text { Observed (196) } \\
\text { Expected }\end{array}$ & $\ddot{*}$ & $\begin{array}{l}32 \\
33 \cdot 2\end{array}$ & $\begin{array}{c}89 \\
109 \cdot 9\end{array}$ & $\begin{array}{l}75 \\
52 \cdot 9\end{array}$ & $13 \cdot 30$ & $0.001<P<0.01$ \\
\hline All Cases* .. & $\cdots$ & . & . & . & $\begin{array}{l}\text { Observed }(1,232)^{*} \\
\text { Expected }\end{array}$ & 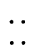 & $\begin{array}{l}178 \\
220 \cdot 9\end{array}$ & $\begin{array}{l}659 \\
664 \cdot 8\end{array}$ & $\begin{array}{l}395 \\
347 \cdot 1\end{array}$ & $14 \cdot 99$ & $P<0.001$ \\
\hline
\end{tabular}

* 32 cases for which a social class could not be assigned have been excluded.

In Table II, the results are presented as Standardized Morbidity Ratios* (that is, as the proportion of observed to expected cases expressed as a percentage).

TABLE II

STANDARDIZED MORBIDITY RATIOS BY DIAGNOSIS AND SOCIAL CLASS

\begin{tabular}{|c|c|c|c|c|c|}
\hline \multirow[b]{2}{*}{ Diagnosis } & \multicolumn{3}{|c|}{ Social Class } & \multirow{2}{*}{$\begin{array}{l}\text { Classified } \\
\text { Cases }\end{array}$} & \multirow{2}{*}{$\begin{array}{c}\text { Number } \\
\text { Un- } \\
\text { classified }\end{array}$} \\
\hline & I and & III & $\begin{array}{c}\text { IV } \\
\text { and V }\end{array}$ & & \\
\hline Schizophrenia & 54 & 86 & 159 & 210 & 8 \\
\hline $\begin{array}{c}\text { Manic-depressive } \\
\text { Psychosis } \ldots\end{array}$ & 97 & 105 & 94 & 352 & 3. \\
\hline $\begin{array}{l}\text { Senile and Arterio- } \\
\text { sclerotic Psychosis }\end{array}$ & 79 & 111 & 98 & 145 & 6 \\
\hline Neurosis & 68 & 109 & 102 & 329 & 6 \\
\hline Other Diagnoses .. & 96 & 81 & 142 & 196 & 9 \\
\hline All Diagnoses & 81 & 99 & 114 & 1,232 & 32 \\
\hline
\end{tabular}

Table III presents the same results in a differentand because of the relatively small numbers involved a rather less satisfactory-form. It may be compared with the Table on p. 89 of the Statistical Review for 1949 (Registrar-General, 1953).

\section{Discussion}

These results confirm previous findings that different rates of mental illness exist among men in different occupational groups. In particular, they

- Adopting the nomenclature suggested by the Registrar-General (General Register Office, 1954b), this ratio might better, perhaps, be called the Standardized Inception Ratio. A disadvantage of the term Standardized Morbidity Ratio is that its initial letters are the same as those of Standardized Mortality Ratio.

\section{TABLE III}

AGE-ADJUSTED RATES PER 100,000 MALES (OCCUPIED AND RETIRED, AGED 15 AND OVER) PER YEAR IN BRISTOL BY SOCIAL CLASS

Average of 5-year totals

\begin{tabular}{|c|c|c|c|c|c|}
\hline \multirow{2}{*}{\multicolumn{3}{|c|}{ Diagnosis }} & \multicolumn{3}{|c|}{ Social Class } \\
\hline & & & \multirow{2}{*}{$\frac{I \text { and II }}{15 \cdot 0}$} & \multirow{2}{*}{$\frac{\text { III }}{23 \cdot 8}$} & \multirow{2}{*}{$\frac{\text { IV and V }}{44 \cdot 1}$} \\
\hline Schizophrenia .. & . & . & & & \\
\hline Manic-depressive & chosis & . & $45 \cdot 0$ & $48 \cdot 6$ & $43 \cdot 7$ \\
\hline Senile and Arteri & $\begin{array}{l}\text { lerotic } \\
\text { chosis }\end{array}$ & & $15 \cdot 1$ & $21 \cdot 2$ & $18 \cdot 8$ \\
\hline Neurosis & .. & .. & $29 \cdot 5$ & $47 \cdot 2$ & $44 \cdot 3$ \\
\hline All Diagnoses & $\ldots$ & .. & $131 \cdot 6$ & $160 \cdot 6$ & $185 \cdot 7$ \\
\hline
\end{tabular}

confirm the finding that schizophrenia is commoner among unskilled and semi-skilled workers than among the skilled and professional classes, but that manic-depressive psychosis is more or less equally common in all classes.

The possible explanations of these findings have been discussed by previous investigators and will only be mentioned briefly here. In view of the accumulated evidence obtained in different populations by different methods, it seems reasonable to reject the suggestion that the apparent class differences are due to fallacies in technique (e.g. failure to allow for the alleged fact that in betterclass patients, physicians tend to give the more hopeful diagnosis of manic-depressive psychosis rather than the gloomy one of schizophrenia). Hollingshead and Redlich (1954), while concluding that there are real class differences among schizophrenics under psychiatric care, raise the question 
whether this would still be so in a "true prevalence study" (i.e. a study in which every member of a given population was psychiatrically examined so that cases of schizophrenia who had never come under care would be ascertained). But the idea of a true prevalence study is less simple than might at first sight appear. Quite apart from formidable practical difficulties (the population studied must number at least tens of thousands, every member of which should, ideally, be seen by a psychiatrist) there are theoretical difficulties.

A schizophrenic who has not come under medical care is likely to be a mild, "borderline" case; there are all grades between the individual who is merely odd, peculiar, or eccentric and the individual who is frankly schizophrenic; the decision where to make the dividing line is bound to be subjective, and yet that decision must have a dominating effect on the results, for the number of persons who are peculiar "or eccentric greatly exceeds those who are undoubtedly schizophrenic. The problem has been discussed by Dunham (1953) who considers it more practical to take the view that mental illness may be defined by the fact of relatives seeking medical advice; on such a view, cases under psychiatric care give a true index of prevalence.*

If it is accepted that there are real class differences among psychiatric patients in the general population, what is their significance? Three main explanations have been advanced:

(1) It is suggested that "pre-schizophrenic" persons, because of their increasing social inadequacy, are able to hold only progressively poorlypaid employment, so that, by the time they become frankly ill, they are to be found in the less skilled and lower-paid occupations.

This is the hypothesis of "drift" which was also advanced to explain the findings of Faris and Dunham (1939) on the ecological distribution of schizophrenics in Chicago. The work of Hollingshead and Redlich (1954) and of Hollingshead, Ellis, and Kirby (1954), however, indicates that where there is a change in social class between a mentally ill patient and his parents, this is more often in the upward than in the downward direction.

(2) The class differences in schizophrenics reflect differences in treatment and rehabilitation. That such differences in treatment exist is undoubted (see, for example, Schaffer and Myers, 1954; and Redlich,

\footnotetext{
* For this conclusion to be true in Great Britain, two assumptions are necessary. Firstly, that there is no gross discrepancy between the required and the available psychiatric facilities - a reasonable assumption in Bristol; secondly, that general practitioners do not differ greatly in the use they make of the psychiatric facilities-a more doubtful assumption.
}

Hollingshead, and Bellis, 1954), but it is hard to see why they should lead to class differences in schizophrenia and not in manic-depressive psychosis. Hollingshead and Redlich (1954), in their New Haven study, counted only those cases active on a particular day; as it is probably true that upperclass schizophrenics are more in and out of treatment, this might account for there being fewer upper-class schizophrenics in treatment at a given moment. But this argument would not apply to incidence studies such as that of Clark (1949) or the present one where the same class differences have been found. Again, it seems probable that upperclass patients are more likely to be treated as out-patients than are lower-class patients, and this might account for the class differences found in studies of hospitalized cases; but the same differences have been found in studies that include out-patient cases (Tietze and others, 1941; Hollingshead and Redlich, 1954).

(3) It is perhaps to the credit of epidemiologists in the field of psychiatry that they have been reluctant to accept the third explanation of the observed class differences - that these reflect the varying stress due to differences in social and economic conditions. The class differences observed in mental disorder are similar to those observed in conditions such as infant mortality, respiratory tuberculosis, chronic rheumatic heart disease, and chronic bronchitis (Registrar-General, 1954) - conditions in which social factors are usually presumed and in some instances have been demonstrated. Though some studies suggest a relation between certain types of mental illness and the cluster of factors at present subsumed under the title of "social isolation"*, not enough work has yet been done to allow reasonably firm conclusions to be drawn about the role of particular social factors in mental illness. It does seem reasonable to conclude, however, that such factors are present.

\section{SUMMARY}

(1) The relation between social class and mental illness in Bristol has been studied in 1,264 male patients admitted to mental hospitals during a 5-year period.

(2) The distribution of schizophrenia among the classes differed very significantly from random, there being a social gradient with a marked excess of cases in Social Classes IV and V. The distribution of manic-depressive psychosis and of senile and

\footnotetext{
Gerard and Houston (1953), Jaco (1954), Gruenberg (1954); see also Hare (1952) and Lemkau (1955) for a general summary and discussion, and an interesting article by Hebb (1955) reporting results of experimental isolation in animals and man.
} 
arterio-sclerotic psychoses did not differ significantly from random. Among neurotics, there was a deficiency of cases in Social Classes I and II, and an excess in Class III. The total incidence of mental illness also showed a social gradient, with an excess of cases in the lower classes.

(3) The sources of error in the investigations are considered and the results briefly discussed.

(4) The results confirm those of previous investigations in other countries.

This work was aided by a grant from the Medical Research Council. My grateful thanks are due to Mrs. M. J. Woollam for clerical assistance and to Miss E. H. Duncan for advice and criticism.

\section{REFERENCES}

Clark, R. E. (1948). Amer. sociol Rev., 13, 325. - (1949). Amer. J. Sociol., 54, 433.

Dunham, H. W. (1953). Amer. J. Psychiat., 109, 567.

Faris, R. E. L. and Dunham, H. W. (1939). "Mental Disorders in Urban Areas". University of Chicago Press, Chicago.
General Register Office (1951). "Classification of Occupations, 1950". H.M.S.O., London.

(1952). "Census 1951, Great Britain: One per cent. Sample Tables". H.M.S.O., London.

(1954a). "Census 1951. England Wales, County Report, Gloucestershire". H.M.S.O, London.

(1954b). "Studies on Medical and Population Subjects, No. 8, Measurement of Morbidity". H.M.S.O., London.

Gerard, D. L., and Houston, L. G. (1953). Psychiat. Quart., 27, 90. Gruenberg, E. M. (1954). Amer. J. Psychiat., 110, 888.

Hare, E. H. (1952). J. ment. Sci., 98, 579.

Hebb, D. O. (1955). Amer. J. Psychiat., 111, 826.

Hollingshead, A. B., and Redlich, F. C. (1953). Amer. sociol. Rev. $18,163$.

18, (1954). Amer. J. Psychiat., 110, 695.

, Ellis, R., and Kirby, E. (1954). Amer. sociol. Rev., 19, 577.

Jaco, E. G. (1954). Amer. sociol. Rev., 19, 567.

Lemkau, P. V. (1955). Amer. J. Psychiat., 111, 801.

Redlich, F. C., Hollingshead, A. B., and Bellis, E. (1954) "Social Class Differences in Attitudes toward Psychiatry". Yale University Press.

Registrar-General (1953). "Statistical Review of England and Wales for the year 1949; Supplement' on General Morbidity, Cancer and Mental Health", p. 89. H.M.S.O., London.

(1954). "Decennial Supplement, England and Wales, 1951: Occupational Mortality", Part I. H.M.S.O., London.

Schaffer, L., and Myers, J.' K. (1954). Psychiatry, 17, 83.

Schaffer, L., and Myers, J. K. (1954), Psych
Strömgren, E. (1948). J. ment. Sci., 94, 266

Tietze, C., Lemkau, P., and Cooper, M. (1941). Amer. J. Sociol., 47, 167.

World Health Organization" (1949). "Manual of the International Statistical Classification of Diseases, Injuries, and Causes of Death". H.M.S.O., London. 